\title{
EFEITOS DA FERTILIZAÇÃO MINERAL NA PRODUÇÃO E GERMINAÇÃO DE SEMENTES E NA BIOMASSA DE PLÂNTULAS DE Dalbergia miscolobium Benth. ${ }^{1}$
}

\author{
Klécia Gili Massi²
}

\begin{abstract}
RESUMO - Mesmo adaptadas à baixa fertilidade dos solos, acredita-se que as espécies de plantas do Cerrado seriam capazes de responder a uma maior disponibilidade de nutrientes e alterar sua produtividade. Este estudo teve por objetivo comparar a produção de frutos, massa de frutos e sementes, germinação e comprimento e biomassa das plântulas da espécie arbórea Dalbergia miscolobium entre áreas fertilizadas e não fertilizadas de Cerrado sensu stricto na Reserva Ecológica do IBGE, Distrito Federal, Brasil. Não houve aumento na produção de frutos, na massa de sementes e na biomassa das plântulas de D. miscolobium em resposta ao aumento da disponibilidade de nutrientes minerais no solo. A massa dos frutos e a porcentagem de germinação foram menores em resposta à fertilização, enquanto o comprimento radicular foi maior em plântulas de sementes fertilizadas. Plantas adaptadas aos solos oligotróficos do Cerrado são menos exigentes em nutrientes e possuem estratégias, como a retranslocação de elementos minerais e orgânicos de órgãos senescentes que podem suprir a demanda por nitrogênio, fósforo e potássio necessários para as atividades reprodutivas.
\end{abstract}

Palavras-chave: Adição de nutrientes; Frutificação; Espécie lenhosa.

\section{EFFECTS OF MINERAL FERTILIZATION ON SEED PRODUCTION, GERMINATION AND SEEDLING BIOMASS OF Dalbergia miscolobium Benth.}

\begin{abstract}
Even adapted to poor soil conditions, Cerrado plants may respond to higher nutrient availability and change their crop production. The aim of this study was to compare the fruit-production, fruit and seed mass, germination, seedlings length and biomass of Dalbergia miscolobium trees growing in fertilized and non-fertilized Cerrado sensu strict plots in Reserva Ecológica do IBGE, Distrito Federal, Brazil. Nutrient addition did not increase fruit-production, seed mass and seedling biomass of $\boldsymbol{D}$. miscolobium. Fruit mass and seed germination were lower in fertilized plants; root length was higher in seedlings from fertilized seeds. Thus, plants adapted to the oligotrophic soils of Cerrado are less demanding in nutrients and have strategies such as retranslocation of mineral and organic elements of senescent organs that can meet the demand for nitrogen, phosphorus and potassium needed for reproductive activities.
\end{abstract}

Keywords: Nutrients Addition; Fruiting; Woody species.

${ }^{1}$ Recebido em 20.02.2015 aceito para publicação em 21.10.2015.

${ }^{2}$ Universidade de Brasília, Programa de Pós-Graduação em Ecologia, Brasília, DF, Brasil. E-mail: <kleciagili@hotmail.com>. 


\section{INTRODUÇÃO}

O processo de formação de flores, frutos e sementes é caro energeticamente (ABRAHAMSON; CASWELL, 1982) e se reflete em distintas estratégias de alocação de recursos para a progênie. A disponibilidade de nutrientes minerais no solo pode ser um dos recursos limitantes à formação de flores, frutos e sementes (CHAPIN, 1980) e, desse modo, a adição de nutrientes poderia levar a um aumento no investimento reprodutivo (HAIG; WESTOBY, 1988). De fato, Lomônaco e Reis (2007) mostraram que, em área de solo mais rico, a espécie arbórea de Cerrado Miconia falax apresentou frutos com maior biomassa, contendo sementes maiores do que os frutos da área de solo nutricionalmente mais pobre. Os efeitos maternais sobre as sementes podem se refletir também no sucesso das plântulas (ROACH; WULFF, 1987; van MÖLKEN et al., 2005). Por exemplo, Nietsche et al. (2004) verificaram que o aumento da massa das sementes levou a maiores porcentagens de germinação, sobrevivência e crescimento das plântulas de Eugenia dysenterica.

A natureza distrófica dos solos do Cerrado (HARIDASAN, 2008), combinada com a estacionalidade climática (EITEN, 1982) e com os efeitos de queimadas (COUTINHO, 1982), desempenha papel importante na composição florística, distribuição, crescimento e reprodução das espécies nativas dessa savana (HOFFMANN et al., 2012). Mesmo adaptadas à baixa fertilidade dos solos (RIZZINI, 1976; RUGGIERO et al., 2002; HARIDASAN, 2008), acredita-se que as espécies de plantas do Cerrado seriam capazes de responder a uma maior disponibilidade de nutrientes, alterando sua produtividade (VILLELA; HARIDASAN, 1994; SASSAKI; FELIPE, 1998; BUCCI et al., 2006) de produzir maior quantidade de frutos e sementes mais pesados, que tenderão a germinar mais e originar plântulas maiores.

A melhor maneira de se testar essa capacidade é através de um experimento de adição de nutrientes (DITOMMASO; AARSSEN, 1989), especialmente se realizado em condições de ambiente natural. Assim, este estudo teve por objetivo comparar a produção de frutos, massa de frutos e sementes, germinação de sementes e comprimento e biomassa das plântulas da espécie arbórea Dalbergia miscolobium entre áreas fertilizadas e não fertilizadas de cerrado sensu stricto no Distrito Federal.

\section{MATERIAL E MÉTODOS}

O estudo foi realizado na Reserva Ecológica do IBGE (RECOR), localizada a $35 \mathrm{~km}$ ao Sul do Centro de Brasília, com coordenadas de $15^{\circ} 55^{\prime}$ a $15^{\circ} 58^{\prime} \mathrm{S}, 47^{\circ} 52^{\prime}$ a $47^{\circ} 55^{\prime} \mathrm{W}$ e altitude variando de 1.048 a $1.160 \mathrm{~m}$. A fitofisionomia dominante na reserva é o cerrado lato sensu, o qual se apresenta sob a forma de campo sujo, campo cerrado, cerrado sensu stricto e cerradão, em um gradiente crescente de biomassa arbórea. Os solos predominantes são os Latossolos Vermelho-Amarelos (RIBEIRO, 2011). A precipitação, umidade relativa e temperatura média anuais registradas na estação meteorológica do IBGE de 2010-2012 foram de 1.418 $\mathrm{mm}, 67 \%$ e $22{ }^{\circ} \mathrm{C}$, respectivamente (RECOR, 2013). O clima é sazonal, com uma estação seca que se estende de maio a setembro; os meses de junho a agosto são os mais secos (RECOR, 2013).

O experimento contou com dois tratamentos (controle e adição de nutrientes: calcário, macro e micronutrientes) e três replicações. Foram demarcadas três parcelas de $10 \mathrm{~m}$ x $30 \mathrm{~m}$, com bordas de $10 \mathrm{~m}$ entre as parcelas, em área de cerrado sensu stricto. Cada parcela foi subdividida em três subparcelas de $10 \mathrm{~m}$ x $10 \mathrm{~m}$, para fins de amostragem.

A adição de nutrientes $\left(100 \mathrm{~kg} \mathrm{ha}^{-1}\right.$. ano ${ }^{-1}$ de N, P e K cada e $18 \mathrm{~kg} \mathrm{ha}^{-1}$. ano ${ }^{-1}$ de $\mathrm{Zn}, 6 \mathrm{~kg} \mathrm{ha}^{-1}$. ano ${ }^{-1} \mathrm{de} \mathrm{Fe}$,

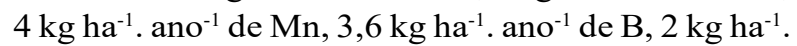
ano $^{-1}$ de Mo e $1,6 \mathrm{~kg} \mathrm{ha}^{-1}$. ano ${ }^{-1} \mathrm{de} \mathrm{Cu}$, como fertilizante composto granulado; e $300 \mathrm{~kg} \mathrm{ha}^{-1}$. ano ${ }^{-1} \mathrm{de} \mathrm{Ca} \mathrm{e} \mathrm{Mg}$, como calcário dolomítico) ocorreu em duas épocas, no início e meio da estação chuvosa. A aplicação foi feita a lanço, para assegurar distribuição uniforme dos fertilizantes anualmente desde 2005. Em março de 2010, foram coletadas amostras simples da camada superficial $(0-15 \mathrm{~cm})$ do solo em intervalos de $10 \mathrm{~m}$, as quais, misturadas, formaram uma amostra composta (GEIGER et al., 2011). A avaliação da fertilidade do solo indicou que houve aumento significativo na disponibilidade de fósforo, potássio, zinco, cobre, cálcio e magnésio e houve redução dos níveis de alumínio nas parcelas adubadas.

A espécie estudada, Dalbergia miscolobium Benth. (Fabaceae), é arbórea típica e abundante dos Cerrados do Planalto Central (FONSECA; SILVA-JÚNIOR, 2004), popularmente conhecida como jacarandá-docerrado, cuja distribuição compreende desde o Estado do Piauí até o Paraná. Os indivíduos em geral apresentam comportamento brevidecíduo característico, com 
caducifolia total e renovação de folhas limitada a duas semanas, geralmente entre agosto e setembro (LENZA; KLINK, 2006). Normalmente, floresce ao final da estação chuvosa, passando grande parte da estação seca na fase de formação e amadurecimento dos frutos, que são dispersos pelo vento ao final dessa estação (BRAZ et al., 2009). Em geral, cada fruto possui uma única semente, mas há registros de duas sementes por fruto.

A avaliação fenológica quantitativa, proposta por Fournier (1974), permite estimar a porcentagem de intensidade da frutificação em cada indivíduo e foi realizada no mês de julho de 2011 (mês em que a espécie estava com frutos maduros), utilizando-se uma escala de cinco categorias: $0,1,2,3$ e 4 (sendo $0=$ ausencia da fenofase; $1=$ magnitude entre $1 \%$ e $25 \% ; 2=$ entre de $26 \%$ e $50 \%$; $3=$ entre $51 \%$ e $75 \%$; e $4=$ entre 76 e $100 \%$ ). A intensidade média de frutificação em cada tratamento foi calculada como $\mathrm{I}_{\text {médio }}=$ $\left(\left(\mathrm{n}_{0} * 0\right)+\left(\mathrm{n}_{1} * 1\right)+\left(\mathrm{n}_{2} * 2\right)+\left(\mathrm{n}_{3} * 3\right)+\left(\mathrm{n}_{4} * 4\right)\right) / \mathrm{N}$, em que $\mathrm{n}_{0}, \mathrm{n}_{1}$, $\mathrm{n}_{2}, \mathrm{n}_{3}$ e $\mathrm{n}_{4}$ são o número de indivíduos observados em cada uma das intensidades de frutificação e N, o número total de indivíduos observados ( $\mathrm{n}=5 /$ tratamento).

No mesmo mês foram coletados frutos maduros de seis indivíduos, três localizados nas parcelas adubadas e três nas não adubadas. As matrizes representaram a diversidade intraespecífica encontrada no local, no que se refere a altura, diâmetro e quantidade de folhas nas copas das árvores. Após a coleta, os frutos foram limpos, descartando-se sementes que apresentavam injúria mecânica ou problema fitossanitário. A massa dos frutos e das sementes foi determinada, sendo as sementes utilizadas nos experimentos de germinação. Foram pesadas 102 sementes, provenientes das três matrizes em cada tratamento.

As sementes foram descascadas, desinfetadas em solução de hipoclorito $10 \%$, lavadas em água destilada e, em seguida, germinadas em rolo de papel a $25{ }^{\circ} \mathrm{C}$, com fotoperíodo de $12 \mathrm{~h}$. Foram feitas quatro repetições com número variável de sementes por matriz, mantendo cada matriz separada. As observações de germinação foram diárias, e o critério de germinação adotado foi a protrusão de radícula maior que $2 \mathrm{~mm}$. Foram calculados o tempo médio e a porcentagem de germinação $(\mathrm{n}=$ 40/tratamento).

Conforme as sementes germinavam, elas eram plantadas em bandeja com vermiculita e mantidas em sala de crescimento. As regas ocorreram a cada dois dias e, ao final de 30 dias, todas as plântulas (40 por tratamento) foram medidas e, depois, secas em estufa e pesadas. O período de tempo de 30 dias refere-se ao período de maior dependência de plântulas dessa espécie das reservas armazenadas no cotilédone (SASSAKI; FELIPE, 1998).

Os dados foram testados quanto à normalidade (teste de Shapiro-Wilk) e a distribuição dos dados, normal. Assim, os tratamentos (sem e com fertilizantes) foram comparados entre si, pelo teste $\mathrm{T}$ a $5 \%$ de probabilidade. As análises foram processadas no programa JMP Pro 10.0 .

\section{RESULTADOS}

Em média, ambas as parcelas produziram a mesma quantidade de frutos $\left(\mathrm{I}_{\text {médio }}=1\right.$, ou seja, entre 1 e $25 \%$ da copa ocupada por frutos; $\mathrm{t}=-0,38$; $\mathrm{e}=0,6776)$. O único indivíduo que apresentou de 76 a $100 \%$ da copa com frutos estava na parcela adubada. A massa dos frutos foi maior nas plantas não adubadas $(\mathrm{t}=$ $3,91 ; \mathrm{p}<0,0001)$, mas a massa das sementes não diferiu significativamente entre os tratamentos $(t=1,03 ; p$ =0,2786; Tabela 1).

A porcentagem de germinação foi maior nas sementes provenientes de plantas controle $(\mathrm{t}=1,73 ; \mathrm{p}=0,0356$; Tabela 1), mas o tempo médio de germinação não mudou em função dos tratamentos $(t=0,10 ; p=0,9105$; Tabela 1). As sementes iniciaram sua germinação no segundo dia após o início do experimento, e a maioria delas germinou entre o quarto e o sexto dia do experimento. A espécie levou duas semanas para alcançar a máxima porcentagem de germinação, tanto das sementes oriundas de plantas adubadas quanto das de plantas não adubadas (Figura 1).

As biomassas aérea e radicular das plântulas não foram afetadas pela adubação $(\mathrm{t}=0,68 ; \mathrm{p}=0,5309$; $\mathrm{t}=0,32$; e $\mathrm{p}=0,7119$, respectivamente; Tabela 1$). \mathrm{O}$ comprimento radicular das plântulas oriundas de sementes fertilizadas foi maior do que o das plântulas originadas de sementes controle $(t=2,08$; e p $=0,0449)$, mas o comprimento da parte aérea não mudou com a fertilização $(\mathrm{t}=-1,54$; e $\mathrm{p}=0,2018$; Tabela 1). Independentemente do tratamento, a biomassa e comprimento da parte radicular foram sempre maiores do que a biomassa e o comprimento da parte aérea $(\mathrm{t}=2,59 ; \mathrm{p}=0,0305 ; \mathrm{e} \mathrm{t}=9,30 ; \mathrm{p}<0,0001$, respectivamente).

Revista Árvore, Viçosa-MG, v.39, n.6, p.1039-1046, 2015 


\section{DISCUSSÃO}

A despeito da adição de fertilizantes e da significativa diferença na disponibilidade de alguns nutrientes no solo, as plantas fertilizadas produziram a mesma quantidade de frutos que as não fertilizadas. Estudos indicaram aumento da colheita da bananeira (BRASIL et al., 2000) e da laranjeira (FIDALSKI et al., 1999), entre outras culturas agrícolas, em função da adubação. Também em ambientes naturais, maior produção de sementes foi observada em algumas espécies herbáceas,

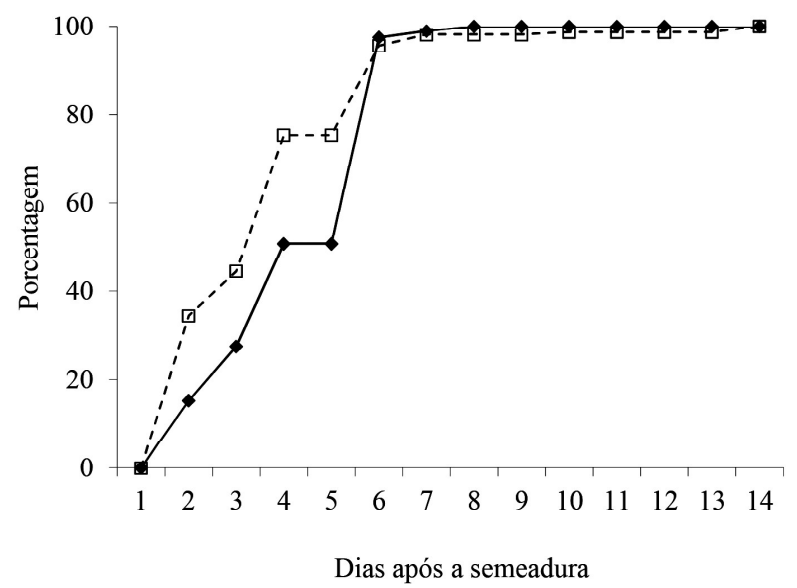

Figura 1-Germinação de Dalbergia miscolobium nos tratamentos sem (linha tracejada) e com fertilizantes (linha cheia).

Figure 1-Germination of Dalbergia miscolobium in the nonfertilized (dashed line) and fertilized treatments (full line). como Daucus carota, Picris hieracioides e Scabiosa columbaria (VERKAAR; SCHENKEVELD, 1984), e na espécie arbórea Sorbus aucuparia (SPERENS, 1997). Como a adição de nutrientes não acarretou aumento no número de frutos e sementes produzidos; esperavase que o faria produzindo sementes mais pesadas, pois se assume existir um trade-off entre quantidade e massa da prole (LORD; WESTOBY, 2006; GREENWAY; HARDER, 2007), o que não foi observado. Esses resultados corroboram os de Lomônaco e Reis (2007), que constataram que o mesmo número e peso de frutos foram produzidos por Matayba guianensis em condições de solo mais ricos em nutrientes.

Normalmente, sementes pequenas tendem a germinar em menor proporção do que as grandes (ROACH; WULFF, 1987; van MÖLKEN et al., 2005), o que foi verificado em Dalbergia miscolobium em outro estudo (SASSAKI; FELIPE, 1999). Nesta pesquisa, o efeito do tratamento não foi significativo sobre a massa das sementes e, consequentemente, não exerceu influência sobre o tempo médio de germinação, mas a porcentagem de germinação foi reduzida em sementes originadas de plantas adubadas. Tal redução não pode ser relacionada à alteração da composição nutricional das sementes, pois resultados preliminares (dados não apresentados) demonstraram que o teor de carboidratos e lipídeos não mudou em função da fertilização.

Independentemente dos efeitos do tratamento, as sementes de $D$. miscolobium germinaram rapidamente (no segundo dia) e em alta porcentagem (em duas semanas,

Tabela 1 - Massa dos frutos e sementes; tempo médio e porcentagem de germinação de sementes; e biomassa e comprimento, aéreo e radicular, de plântulas de Dalbergia miscolobium nos tratamento sem e com fertilizantes ( $\mathrm{n}=3$ indivíduos). Dados expressos como média \pm desvio-padrão.

Table 1 - Fruit and seed mass, average germination time and germination percentage; biomass and length of shoot and root in seedlings of Dalbergia miscolobium in non-fertilized and fertilized treatments $(n=3$ individuals). Data showed as mean \pm standard deviation.

\begin{tabular}{lcc}
\hline & & Tratamentos \\
\cline { 2 - 3 } Com fertilizantes & Sem fertilizantes & $129 \pm 43 \mathrm{~b}$ \\
Massa dos frutos (mg) & $153 \pm 37 \mathrm{a}$ & $66 \pm 22 \mathrm{a}$ \\
Massa das sementes (mg) & $69 \pm 16 \mathrm{a}$ & $73 \pm 20 \mathrm{~b}$ \\
Germinação (\%) & $87 \pm 10 \mathrm{a}$ & $3 \pm 1$ a \\
Tempo médio de germinação (dias) & $3 \pm 1 \mathrm{a}$ & $14 \pm 15 \mathrm{a}$ \\
Biomassa aérea (mg/plântula) & $13 \pm 6 \mathrm{a}$ & $17 \pm 6$ a \\
Biomassa radicular (mg/plântula) & $16 \pm 6 \mathrm{a}$ & $6 \pm 3$ a \\
Comprimento aéreo (cm) & $9 \pm 2 \mathrm{a}$ & $11 \pm 3 \mathrm{~b}$ \\
Comprimento radicular (cm) & $9 \pm 3$ a & \\
\hline
\end{tabular}

Valores seguidos da mesma letra não diferem estatisticamente pelo teste $\mathrm{t}(\mathrm{p}>0,05)$.

Revista Árvore, Viçosa-MG, v.39, n.6, p.1039-1046, 2015 
todas as sementes haviam germinado). Segundo Rossatto e Kolb (2010), a germinação das espécies do Cerrado é variável, mas a estratégia de germinar em grande quantidade e rapidamente aumenta a probabilidade de se estabelecer e sobreviver à próxima estação seca (OLIVEIRA, 1998).

Estima-se que sementes grandes originam plântulas maiores e mais vigorosas do que sementes pequenas (BAKER, 1972), resultado que Sassaki e Felipe (1999) já apresentaram sobre D. miscolobium. Neste trabalho, como a adição de nutrientes não exerceu efeito sobre a massa de sementes, também não o fez sobre a biomassa das partes aérea e radicular e o comprimento da parte aérea. O maior comprimento radicular em plântulas de sementes fertilizadas pode indicar investimento em alongamento dos órgãos subterrâneos. Adicionalmente, o resultado apurado de raízes maiores e mais pesadas do que as partes aéreas (independentemente do tratamento) está de acordo com o de outros trabalhos atestando que o componente subterrâneo representa a maior parte da biomassa total das plantas do Cerrado (ABDALA et al., 1998; HOFFMANN; FRANCO, 2003).

De modo geral, a adubação e a calagem não influenciaram a maioria dos parâmetros da espécie analisada. Dos elementos que apresentaram diferenças entre as áreas fertilizadas e não fertilizadas, aumento na concentração de cálcio poderia ser percebida nas folhas da planta, mas não nos frutos, devido à baixa mobilidade desse mineral no floema; os micronutrientes atuariam na formação e germinação de grãos de pólen e, dessa forma, os minerais nitrogênio, fósforo e potássio, responsáveis pela formação e transporte de fotoassimilados, seriam os mais diretamente envolvidos no preenchimento de frutos e sementes (MARSCHNER, 2012). Não há recomendação de adubação das espécies de plantas de Cerrado, mas em culturas agrícolas a dosagem de fertilização de N, P e K utilizada foi alta $\left(100 \mathrm{~kg} \mathrm{ha}^{-1}\right.$. ano $\left.{ }^{-1}\right)$ (EMBRAPA, 2015).

Apesar da dosagem elevada, a espécie estudada se trata de um organismo lenhoso adulto com processos fisiológicos mais lentos e complexos do que os de plantas como a soja. Exemplo dessa complexidade é que o crescimento de uma árvore adulta é promovido com reservas de substâncias minerais absorvidas um ano antes de serem imobilizadas (LARCHER, 2000). Na área de estudo, a adubação é realizada desde 2005, e acredita-se que os nutrientes devam estar sendo utilizados por todos os hábitos e formas de vida presentes, embora outras pesquisas sejam necessárias para poder afirmar isso e verificar se há espécies de planta retirando mais nutrientes do solo do que outras. Adicionalmente, seria esperado observar diferenças no incremento em diâmetro das plantas entre os tratamentos, em resposta à ausência de efeito da adubação sobre a reprodução (REEKIE; AVILA-SAKAR, 2005). Todavia, alguns resultados preliminares demonstraram que o crescimento das plantas das áreas fertilizadas não foi diferente do crescimento das plantas controle (as primeiras cresceram 15\% e as plantas das áreas controle, $12 \%$ em diâmetro, em cinco anos - dados não apresentados).

Finalmente, plantas adaptadas a solos oligotróficos, como os do Cerrado, são menos exigentes em nutrientes e possuem estratégias como a retranslocação de elementos minerais e orgânicos de órgãos senescentes que podem suprir a demanda por nitrogênio, fósforo e potássio necessária para as atividades reprodutivas (LARCHER, 2000). Na espécie estudada, a caducifolia que ocorre simultaneamente à frutificação pode redirecionar esses elementos das folhas para o preenchimento de frutos e sementes. Também Rizzini (1976) salientou que a emissão de folhas e flores da maioria das plantas do Cerrado depois de toda a estação seca e antes das chuvas confirma a amplitude de reservas nutricionais das plantas que habitam esse bioma. Adicionalmente, a espécie estudada é uma Fabaceae com capacidade de fixação de nitrogênio (CORDEIRO, 2002), o que diminuiria sua demanda por esse elemento nas áreas sem fertilização.

\section{CONCLUSÕES}

Diante dos resultados, apesar da aparente restrição nutricional imposta às espécies do Cerrado, a produção de frutos, a massa de sementes e a biomassa das plântulas da espécie arbórea Dalbergia miscolobium não aumentaram em resposta a um incremento na disponibilidade de nutrientes minerais no solo. A porcentagem de germinação de sementes e a massa dos frutos foram menores em resposta à adubação. O maior comprimento radicular em plântulas de sementes fertilizadas indica um investimento dos recursos em órgãos subterrâneos. Assim, a espécie estudada parece estar adaptada à baixa qualidade nutricional dos solos do Cerrado e deve possuir estratégias para garantir o requerimento de nitrogênio, fósforo e potássio para atividades reprodutivas.

Revista Árvore, Viçosa-MG, v.39, n.6, p.1039-1046, 2015 


\section{AGRADECIMENTOS}

À Reserva Ecológica do IBGE, pela autorização da pesquisa; e à Capes e ao $\mathrm{CNPq}$, pelo financiamento deste trabalho.

\section{REFERÊNCIAS}

ABDALA, G.C.; CALDAS, L.S.; HARIDASAN, M.; EITEN, G. Above and belowground organic matter and root: shoot ratio in a cerrado in central Brazil. Brazilian Journal of Ecology, v.2, n.1, p.11-23, 1998.

ABRAHAMSON, W.G.; CASWELL, H. On the comparative allocations of biomass, energy, and nutrients in plants. Ecology, v.63, n.4, p.982991,1982 .

BAKER, H.G. Seed weight in relation to environmental conditions in California Ecology, v.53, n.6, p.997-1010, 1972.

BRASIL, E.C.; OEIRAS, A.H.L.; MENEZES, A.J.E.A.; VELOSO, C.A.C. Desenvolvimento e produção de frutos de bananeira em resposta à adubação nitrogenada e potássica. Pesquisa Agropecuária Brasileira, v. 35, n.12, p.2407-2414, 2000.

BRAZ, M.S.S.; SOUZA, V.C.; ANDRADE, L.A.; BRUNO, R.L.A.; OLIVEIRA, L.S.B.; SILVA, J.M. Caracterização morfológica de frutos, sementes e plântulas de jacarandá-da-bahia (Dalbergia nigra (Vell.) Fr. All.ex. Benth) Leguminosae-

Papilonoideae. Revista Brasileira de Ciências Agrárias, v.4, n.1, p.67-71, 2009.

BUCCI, S.J.; SCHOLZ, F.G.; GOLDSTEIN, G.; MEINZER, F.C.; FRANCO, A.C.; CAMPANELLO, P.I.; VILLALOBOS-VEGA, R.; BUSTAMANTE, M.; MIRALLES-WILHELM, F. Nutrient availability constrains the hydraulic architecture and water relations of savannah trees. Plant Cell and Environment, v.29, n.12, p.21532167, 2006.

CHAPIN, F.S. The mineral nutrition of wild plants. Annual Review of Ecology and Systematics, v.11, p.233-260, 1980.

CORDEIRO, L. Fixac'aPo de nitrogenio em leguminosas ocorrentes no cerrado. In: KLEIN, A. (Ed.). Eugen Warming e o cerrado brasileiro: um seìculo depois. Sabo Paulo: UNESP, 2002. p.131-145.

COUTINHO, L.M. Ecological effects of fire in Brazilian cerrado. In: HUNTLEY, B.J.; WALKER, B.H. (Ed.). Ecology of tropical savanas. Berlin: Springer, 1982. p.273-291.

DITOMMASO, A.; AARSSEN, L.W. Resource manipulations in natural vegetation: a review. Vegetatio, v.84, n.1, p.9-29, 1989.

EITEN, G. Brazilian savannas. In: HUNTLEY, B.J.; WALKER, B.H. (Ed.). Ecology of tropical savanas. Berlin: Springer, 1982. p.25-47.

\section{EMPRESA BRASILEIRA DE PESQUISA} AGROPECUÁRIA - EMBRAPA. Disponível em: sistemasdeproducao.cnptia.embrapa.br Acesso em: 10 de maio de 2015 .

FIDALSKI, J.; PAVAN, M.A.; AULER, P.A.M.; JACOMINO, A.P. Produção de frutos de laranjeira Pêra e teores de nutrientes nas folhas e no solo, em Latossolo Vermelho-Escuro do noroeste do Paraná. Revista Brasileira de Ciências do Solo, v.23, n.2, p.273-279, 1999

FONSECA, M.S.; SILVA JUNIOR, M.C. Fitossociologia e similaridade florística entre trechos de cerrado sentido restrito em interflúvio e em vale no Jardim Botânico de Brasília, DF. Acta Botanica Brasilica, v.18, n.1, p.19-29, 2004.

FOURNIER, L.A. Un método cuantitativo para la medición de características fenológicas en árboles. Turrialba, v.24, n.4, p.422-423, 1974.

GEIGER, E.L.; GOTSCH, S.G.; DAMASCO, G.; HARIDASAN, M.; FRANCO, A.C.; HOFFMANN, W.A. Distinct roles of savanna and forest tree species in regeneration under fire suppression in a Brazilian savanna. Journal of Vegetation Science, v.22, p.312-321, 2011.

GREENWAY, C.A.; HARDER, L.D. Variation in ovule and seed size and associated size-number trade-offs in angiosperms. American Journal of Botany, v.94, n.5, p.840-846, 2007. 
HAIG, D.; WESTOBY, M. On limits to seed production. American Naturalist, v.131, p.757-759, 1988.

HARIDASAN, M. Nutritional adaptations of native plants of the cerrado biome in acid soils. Brazilian Journal of Plant Physiology, v.20, n.3, p.183-195, 2008.

HOFFMANN, W.A.; FRANCO, A.C. Comparative growth analysis of tropical Forest and savanna woody plants using phylogeneticallyindependent contrasts. Journal of Ecology, n.3, v.91, p.475-484, 2003.

HOFFMANN, W.A.; GEIGER, E.L.; GOTSCH, S.G.; ROSSATTO, D.R.; SILVA, L.C.R. LAU, O.L.; HARIDASAN, M.; FRANCO, A.C. Ecological thresholds at the savanna-forest boundary: how plant traits, resources and fire govern the distribution of tropical biomes. Ecology Letters, v.15, n.7, p.759-768, 2012.

LARCHER, W. Ecofisiologia vegetal. São Carlos: RiMa, 2000. 531p.

LENZA, E.; KLINK, C.A. Comportamento fenológico de espécies lenhosas em um cerrado sentido restrito de Brasília, DF. Revista Brasileira de Botânica, v.29, n.4, p.627-638, 2006.

LOMÔNACO, C.; REIS, N.S. Produção de frutos e sementes em Miconia fallax DC.

(Melastomataceae) e Matayba guianensis Aubl. (Sapindaceae) em duas áreas de Cerrado no Triângulo Mineiro. Revista Biologia Neotropical, v.4, n.1, p.13-20, 2007.

LORD, J.M.; WESTOBY, M. Accessory costs of seed production. Oecologia, v. 150, n.2, p.310317,2006

MARSCHNER, H. Mineral nutrition of higher plants. 3.ed. London: Elsevier, 2012. $643 p$.

van MÖLKEN, T.; JORRITSMA-WIENK, L.D.; van HOEK, P.H.W.; KROON, H. Only Seed Size Matters for Germination in Different Populations of the Dimorphic Tragopogon pratensis subsp. pratensis (Asteraceae). American Journal of Botany, v.92, n.3, p.432-437, 2005.
NIETSCHE, S.; GONÇALVES, V.D.; PEREIRA, M.C.T.; SANTOS, F.A.; ABREU, S.C.; MOTA, W.F. Tamanho da semente e substratos na germinação e crescimento inicial de mudas de cagaiteira. Ciência Agrotécnica, v.28, n.6, p.1321-1325, 2004.

OLIVEIRA, P.E. Fenologia e biologia reprodutiva das espécies de cerrado. In: SANO, S.M.; ALMEIDA, S.P. (Ed.). Cerrado: ambiente e flora. Planaltina: Embrapa, 1998. p.169-192.

RESERVA ECOLÓGICADO IBGE - RECOR.

Disponível em: www.recor.org.br Acesso em: 14 de mar. de 2013.

REEKIE, E.G.; AVILA-SAKAR, G. The shape of the trade-off function between reproduction and growth. In: REEKIE, E.G.; BAZZAZ, F.A. (Ed.). Reproductive allocation in plants. San Diego: Elsevier Academic Press, 2005. p.189-214.

RIBEIRO, M.L. Reserva Ecoloìgica do IBGE: biodiversidade terrestre. Rio de Janeiro: Coordenac'abo de Recursos Naturais e Estudos Ambientais, 2011. v.1. 263p.

RIZZINI, C.T. Tratado de fitogeografia do Brasil: aspectos ecológicos, sociológicos e florísticos. Rio de Janeiro: Âmbito Cultural, 1976. $747 \mathrm{p}$.

ROACH, D.A.; WULFF, R.D. Maternal Effects in Plants. Annual Review of Ecology and Systematics, v.18, p.209-235, 1987.

ROSSATTO, D.R.; KOLB, R.M. Germinação de Pyrostegia venusta (Bignoniaceae), viabilidade de sementes e desenvolvimento pós-seminal.

Revista Brasileira de Botânica, v.33, n.1, p.51-60, 2010.

RUGGIERO, P.G.C.; BATALHA, M.A.; PIVELLO, V.R.; MEIRELLES, S.T. Soil-Vegetation Relationships in Cerrado (Brazilian savanna) and Semideciduous Forest, Southeastern Brazil.

Plant Ecology, v.160, n.1, p.1-16, 2002.

SASSAKI, R.M.; FELIPPE, G.M. Response of Dalbergia miscolobium Benth. seedlings, a cerrado tree species, to mineral nutrient supply. Revista Brasileira de Botânica, v.21, n. 1, p.65-72, 1998.

Revista Árvore, Viçosa-MG, v.39, n.6, p.1039-1046, 2015 
SASSAKI, R.M.; FELIPPE, G.M. Single-Seeded fruits and seedling establishment in Dalbergia miscolobium Benth. (Papilionaceae).

Biotropica, v. 31, n.4, p.591-597.1999.

SPERENS, U. Long-term variation in, and effects of fertiliser addition on, flower, fruit and seed production in the tree Sorbus aucuparia (Rosaceae). Ecography, v.20, p.521-534, 1997.
VERKAAR, H.J.; SCHENKEVELD, A.J. On the ecology of short-lived forbs in chalk grasslands: semelparity and seed output of some species in relation to various levels of nutrient supply. New Phytologist, v.98, n.4, p.673-682, 1984.

VILLELA, D.M.V.; HARIDASAN, M. Response of the ground layer community of a cerrado vegetation in central Brazil to liming and irrigation. Plant and Soil, v.163, n.1, p.25-31, 1994. 